\title{
Sphingosine Kinase-1-Dependent and -Independent Inhibitory Effects of Zanthoxyli Fructus to Attenuate the Activation of Mucosal Mast Cells and Ameliorate Food Allergies in Mice
}

\author{
Xiaoyu Wang, Natsuko Kageyama-Yahara, Shusaku Hayashi, \\ Takeshi Yamamoto, and Makoto Kadowaki \\ Division of Gastrointestinal Pathophysiology, Institute of Natural Medicine, University of Toyama, 2630 Sugitani, Toyama 930-0194, \\ Japan \\ Correspondence should be addressed to Makoto Kadowaki, makotok@inm.u-toyama.ac.jp
}

Received 13 January 2012; Accepted 29 March 2012

Academic Editor: Olumayokun A. Olajide

Copyright () 2012 Xiaoyu Wang et al. This is an open access article distributed under the Creative Commons Attribution License, which permits unrestricted use, distribution, and reproduction in any medium, provided the original work is properly cited.

\begin{abstract}
Food allergy (FA) is relatively a common disease in infants, but effective drug therapies are not yet available. Notably, mucosal mast cells, but not connective-tissue mast cells, play important roles in food allergic reactions via the release of inflammatory mediators. Therefore, we screened medicinal herb extracts for in vitro and in vivo antiallergic activity through inhibiting mucosal mast cell activation. As a result, both antigen-induced and calcium ionophore-induced degranulation was significantly inhibited by Zanthoxyli Fructus water extract (ZF) in mucosal-type murine bone marrow-derived mast cells (mBMMCs). ZF suppressed the antigen-induced $\left[\mathrm{Ca}^{2+}\right]_{i}$ elevation and the antigen-enhanced mRNA expression of TNF- $\alpha$, IL-4, and IL-13. The transcriptome and real-time PCR analyses revealed that ZF greatly decreased the antigen-enhanced expression level of sphingosine kinase 1 (Sphk1), which plays a key role in the FceRI-mediated immune responses in mast cells. Furthermore, ZF inhibited allergic symptoms in an ovalbumin-caused murine FA model and decreased the number of infiltrating mucosal mast cells and the enhanced mRNA expression levels of IL-4 and Sphk1 in the FA mice colons. These results indicate that ZF suppresses mucosal mast cell activities mainly through Sphk1-dependent mechanism, and ZF is utilized for the development of a novel, potent anti-FA agent.
\end{abstract}

\section{Introduction}

Food allergy (FA) is an abnormal immunologic reaction to food proteins. The prevalence of FA in children is estimated to be approximately $4 \%$ to $10 \%$. The greatest prevalence is in the first few years of life, and a gradual decrease occurs during the first decade as tolerance develops [1], although some peanut allergy is rarely outgrown [2].

Although the underlying pathogenic mechanisms of food allergy are not well understood, it is well known that mast cells play central roles in the pathogenesis of various allergic disorders. The activation of mast cells leads to the secretion of various proteases, autacoids, growth factors, cytokines, and chemokines $[3,4]$. Two distinct populations of mast cells exist: mucosal mast cells and connective-tissue mast cells.
Considerable evidence has demonstrated that mucosal mast cells are morphologically, biochemically, and functionally distinct from connective-tissue mast cells [5]. We have previously demonstrated that the number of mucosal mast cells in the colons of our ovalbumin-induced FA model mice is increased [6], and that mucosal mast cells play important roles in the allergic reaction in our FA model [7]. At present, connective tissue mast cell stabilizers (tranilast, ketotifen, and cromolyn) are frequently used for the treatment of various allergic disorders besides FA. These agents have no effect on mucosal mast cells [8]. Until now, there has been little information on the inhibitory agents against mucosal mast cell activation [8-11].

Currently, no therapeutic drugs for FA have been developed, and the avoidance of food antigens is the central 
therapy that is used to prevent further reactions in FA patients. Consequently, novel approaches are being explored to develop innovative medicines. Specifically, traditional medicines have proven to be a potential source for the development of new therapeutic medicines [12]. Many herbal medicines are used as traditional remedies for treating various diseases, which include allergic diseases, particularly in Asian countries. Li et al. [12-14] have reported that Chinese herbal medicines, food allergy herbal formula-1 (FAHF-1) and FAHF-2, ameliorate peanut-induced anaphylaxis in a murine FA model. Furthermore, FAHF-2 reduces allergen-stimulated basophil activation, hyperreleasability, and percentages of circulating basophils in a 6-month clinical trial for patients with food allergy [15]. In addition, we have demonstrated that kakkonto, a traditional medicine that is frequently used in Japan and China, alleviates the allergic symptoms that are induced by food antigens [6]. Therefore, to address the development of new therapeutic medicines for FA, we screened 80 medicinal herbs that are frequently used in Japan using rat-basophilic-leukemia (RBL-) $2 \mathrm{H} 3$ mast-like cells. Of the 80 medicinal herbs, the water extracts of Arecae Semen, Cinnamoni Cortex, Curcumae Rhizoma, Rhei Rhizoma, and Zanthoxyli Fructus significantly inhibited antigen-induced degranulation. Furthermore, we found that Zanthoxyli Fructus water extract exhibited the most potent inhibitory effect in a preliminary study that used our FA model.

Zanthoxylum piperitum De Candolle (ZPDC), a deciduous shrub, is distributed in Japan, China, and Korea. The fruit of ZPDC, which is called Shan-Jiao in Chinese and Sansho in Japanese, is utilized as a spice and a traditional herbal medicine in Asia. It has been reported that glycoproteins in the Zanthoxyli Fructus have anti-inflammatory properties [16]. However, it remains still unclear whether Zanthoxyli Fructus plays a suppressive effect on the activation of mucosal mast cells and the development of FA.

In this study, we investigated the effect of the water extract of the fruit of ZPDC (ZF) on mucosal mast cells, explored the underlying mechanism of the pharmacological effects, and demonstrated for the first time that ZF inhibited the activation of mucosal mast cells in vitro and in vivo primarily through the suppression of antigen-induced sphingosine kinase 1 (Sphk1) gene expression. Therefore, ZF may serve as a leading candidate for the development of novel anti-FA agents.

\section{Materials and Methods}

2.1. Animals. Male BALB/c mice (5 weeks old) were purchased from Japan SLC Inc. (Shizuoka, Japan). All mice were housed with free access to food and water in the experimental animal facility at the University of Toyama. All of the animal care procedures and experiments were approved by the Animal Experiment Committee at the University of Toyama (Authorization no. S-2009 INM-9).

2.2. Reagents. Recombinant murine SCF, recombinant murine IL-3, recombinant murine IL-9, and TGF- $\beta 1$ were purchased from Peprotech (London, UK). N, N-dimethylsphingosine (DMS), 3-O-caffeoylquinic acid, catechin, hyperfine, and epicatechin were purchased from Cayman Chemical (Ann Arbor, MI, USA). Limonene, A23187, ovalbumin (OVA, faction V), propidium iodide (PI), and aluminum hydroxide gel were purchased from Sigma (St. Louis, MO, USA). Cyclosporin A, W-7, and KN-93 were purchased from Calbiochem (San Diego, CA, USA). RPMI1640 medium was purchased from Wako (Osaka, Japan). Antidinitrophenyl (DNP) IgE was purchased from Yamasa (Tokyo, Japan). Fura-2 AM and Fluo-3 AM were purchased from Dojindo (Kumamoto, Japan). Mouse GeneChip Gene 1.0 ST Array was purchased from Affymetrix (Santa Clara, CA, USA). Antiserum against mouse mucosal mast cell protease (mMCP)-1 was purchased from Moredun Scientific (Penicuik, UK). Hydroxy- $\alpha$-sanshool was provided by Tsumura Co. (Tokyo, Japan). Sepasol Super was purchased from Nacalai Tesque (Kyoto, Japan). RNeasy Plus Micro was procured from Qiagen (Hilden, Germany).

2.3. Preparation of Extracts. The water extracts of medicinal herbs were provided by the Joint Usage/Research Center for Science-Based Natural Medicine, Institute of Natural Medicine, University of Toyama and the Knowledge Cluster Initiative Program (Second Stage) from the Ministry of Education, Culture, Sports, Science and Technology of Japan. Briefly, crude herbs $(45.0 \mathrm{~g})$ were extracted with $900 \mathrm{~mL}$ of hot water under reflux conditions. Following filtration through a cotton-inserted funnel, the extract was lyophilized for 2 days. The yield of ZF was 19.8\% $(w / w)$. Quality control of ZF was performed by an LC-MS analysis using a LC-IT-TOF mass spectrometer equipped with an ESI interface (Shimadzu LC-IT-TOF MS ESI, Shimadzu Scientific Instruments, Kyoto, Japan). The mass spectrometry data that were obtained from the extract were registered in the Wakan-Yaku DataBase system at the Institute of Natural Medicine of the University of Toyama (http://wakandb.u-toyama.ac.jp/wiki/LCMS:Zanthoxyli_ Fructus/10025907).

2.4. Cell Culture. The RBL-2H3 cells were kindly provided by Dr. Hidetaka Yakura (Tokyo Metropolitan Institute for Neuroscience, Tokyo, Japan) and maintained in complete RPMI1640 medium. The mucosal-type murine bone marrowderived mast cells (mBMMCs) were prepared from the femurs of $\mathrm{BALB} / \mathrm{c}$ mice as described previously $[9,17]$. Briefly, the bone marrow cells were cultured in complete RPMI- 1640 medium that contained $40 \mathrm{ng} / \mathrm{mL}$ SCF, $20 \mathrm{ng} / \mathrm{mL}$ IL-3, $5 \mathrm{ng} / \mathrm{mL}$ IL-9, and $1 \mathrm{ng} / \mathrm{mL}$ TGF- $\beta 1$ for 4 weeks. The mast cell purity was examined by flow cytometry (FACS Calibur; Becton Dickinson, Franklin Lakes, NJ, USA), and more than $98 \%$ of the nonadherent cells were high-affinity IgE receptor (FceRI) and c-kit positive (data not shown).

2.5. Activation of RBL-2H3 Cells and mBMMCs. The activation of RBL-2H3 cells and mBMMCs was performed as previously described [9]. Briefly, the RBL-2H3 cells and mBMMCs were sensitized with $0.5 \mu \mathrm{g} / \mathrm{mL}$ and $1.5 \mu \mathrm{g} / \mathrm{mL}$ 
anti-DNP IgE for $24 \mathrm{~h}$ and $6 \mathrm{~h}$, respectively, at $37^{\circ} \mathrm{C}$. The cells were washed and incubated with medicinal herb extracts or test drugs. After $30 \mathrm{~min}$, the cells were stimulated with $100 \mathrm{ng} / \mathrm{mL}$ DNP-BSA at $37^{\circ} \mathrm{C}$ for $1 \mathrm{~h}$; the samples were then centrifuged, and the supernatants and cell pellets were collected for use in the degranulation assay, real-time PCR analysis, and transcriptome analysis. In the experiments that utilized calcium ionophore, the RBL-2H3 cells and mBMMCs were incubated with ZF or test drugs for $30 \mathrm{~min}$, and the cells were then stimulated with $25 \mu \mathrm{M}$ calcium ionophore A23187 for $30 \mathrm{~min}$.

2.6. Degranulation Assay. The degree of degranulation was assessed by measuring $\beta$-hexosaminidase release, which has been previously described [9]. The extent of degranulation was calculated by dividing the absorbance of the supernatant by the sum of absorbances of the supernatant and cell lysate.

2.7. Viability Analysis by PI Staining. The mBMMCs that were pretreated with $\mathrm{ZF}$ for $90 \mathrm{~min}$ at $37^{\circ} \mathrm{C}$ in a humidified $5 \% \mathrm{CO}_{2}$ atmosphere were washed twice with fluorescenceactivated cell sorter (FACS) buffer (1\% BSA and $0.2 \% \mathrm{NaN}_{3}$ in PBS), and the cells were then resuspended in FACS buffer in polystyrene round-bottom tubes. After staining with $2 \mu \mathrm{g} / \mathrm{mL}$ PI, the viability of the cells was examined using the FACS Calibur system.

2.8. Intracellular Calcium Measurement. Cross-linking of FceRI by antigens induces mast cell activation, which leads to the elevation of the intracellular calcium concentration $\left(\left[\mathrm{Ca}^{2+}\right]_{i}\right)$ prior to the exocytosis of granules and cytokines [4]. The measurement of $\left[\mathrm{Ca}^{2+}\right]_{i}$ was performed as previously described [8]. Briefly, the sensitized mast cells were loaded with $5 \mu \mathrm{M}$ Fura-2 AM in loading buffer. The fluorescence was measured at 340 and $380 \mathrm{~nm}$ using a model F-4500 fluorescence spectrophotometer intracellular $\mathrm{Ca}^{2+}$ measurement system (Hitachi, Tokyo, Japan), and the background-corrected 340:380 ratio was calibrated.

For an experiment with calcium ionophore A23187, the calcium imaging experiments were performed using the AQUACOSMOS IMAGO CCD camera-based system (HAMAMATSU, C7773, Hamamatsu, Japan). The cells were loaded with $10 \mu \mathrm{M}$ Fluo-3 AM in loading buffer for $30 \mathrm{~min}$; they were washed once and were then monitored for $4 \mathrm{~min}$ at $310 \mathrm{~nm}$.

2.9. Transcriptome Analyses. The global gene expression analysis was performed using an Affymetrix Mouse GeneChip Gene 1.0 ST Array that was spotted with 28,853 probe sets. The total RNA was isolated from mBMMCs using the RNeasy Plus Micro kit according to the manufacturer's instructions, and the mRNA for the array hybridization was prepared as described in the GeneChip Expression Technical Manual. The data were first analyzed using the GeneChip Analysis Suite Software (Affymetrix) and were further analyzed using Gene-Spring software (Silicon Genetics, CA, USA) to identify the significant genes. The fold-change $\log _{2}$ ratio is the change in the expression level of a transcript that is expressed as the $\log _{2}$ ratio (the fold-change $\log _{2}$ ratio of 1 and -1 are equal to a fold change of 2 and 0.5 , resp.).

2.10. Allergic Diarrhea Induction in a Murine FA Model. Male $\mathrm{BALB} / \mathrm{c}$ mice were sensitized twice at a 2-week interval by intraperitoneal injection with $50 \mu \mathrm{g}$ of OVA in the presence of $1.3 \mathrm{mg}$ of aluminum hydroxide gel as an adjuvant. Two weeks after systemic priming, the mice were repeatedly given $50 \mathrm{mg}$ of OVA that was dissolved in $0.3 \mathrm{~mL}$ of water using intragastric feeding needles every other day. Diarrhea was assessed by visually monitoring the mice for up to $1 \mathrm{~h}$ following the intragastric challenge. For treatment with $\mathrm{ZF}$ (32, 100 and $320 \mathrm{mg} / \mathrm{kg}$ body weight) or DMS ( $1 \mathrm{mg} / \mathrm{kg}$ body weight) in the FA model, the agents were orally administered to the mice each day throughout the period of oral OVA administration, and they were administered $1 \mathrm{~h}$ prior to the OVA challenge.

For histological analysis, the proximal colon was excised $1 \mathrm{~h}$ after the fifth or sixth oral OVA challenge and stained using antibodies against mMCP-1 according to the procedure that was described previously [6].

2.11. Real-Time PCR. Total RNA was extracted from the proximal colon using the Sepasol Super according to the manufacturer's instructions. Quantitative real-time PCR was performed as previously described [6]. The following primer pairs were used: IL-4 forward: $5^{\prime}$-GGT CTC AAC CCC CAG CTA GT- $3^{\prime}$ and reverse: $5^{\prime}$-GCC GAT GAT CTC TCT CAA GTG AT-3' ${ }^{\prime}$ IL-13 forward: 5'-GGA TAT TGC ATG GCC TCT GTA AC-3' and reverse: $5^{\prime}$-AAC AGT TGC TTT GTG TAG CTG A-3'; TNF- $\alpha$ forward: $5^{\prime}$-AAG CCT GTA GCC CAC GTC GTA-3' and reverse: $5^{\prime}$-GGC ACC ACT AGT TGG TTG TCT TTG-3'; Sphk1 forward: $5^{\prime}$-AGT CGC CAG ACA CCC TCC TG-3' and reverse: $5^{\prime}$-CCT CGA GGG CAT TCT GGT TCC-3' ${ }^{\prime}$; GAPDH forward: $5^{\prime}$-TGA CCA CAG TCC ATG CCA TC-3' and reverse: $5^{\prime}$-GAC GGA CAC ATT GGG GGT AG-3'. The target mRNA was normalized to GAPDH mRNA as an internal control in each sample. Results were expressed as the relative ratio to the control group average (1 in vehicle-treated mBMMCs without DNP-BSA stimulation or the proximal colons of vehicle-treated FA mice).

2.12. Statistical Analysis. Data are presented as the mean \pm SD. The statistical comparisons were performed using Student's $t$-test and repeated measures one-way ANOVA followed by post hoc Dunnett's test or chi-square test with SPSS software (version 19, IBM, Somers, NY, USA). Values of $P<0.05$ were considered significant.

\section{Results}

3.1. Water Extracts of Arecae Semen, Cinnamoni Cortex, Curcumae Rhizoma, Rhei Rhizoma, and Zanthoxyli Fructus Inhibit Antigen-Stimulated Degranulation in RBL-2H3 Cells. Eighty medicinal herb extracts were screened for their inhibitory effect on DNP-BSA-stimulated degranulation in RBL-2H3 cells. The water extracts of Arecae Semen, Cinnamoni Cortex, Curcumae Rhizoma, Rhei Rhizoma, and 


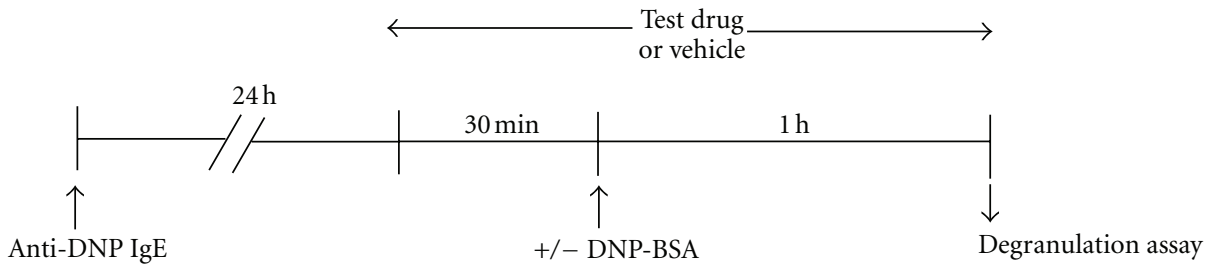

(a)
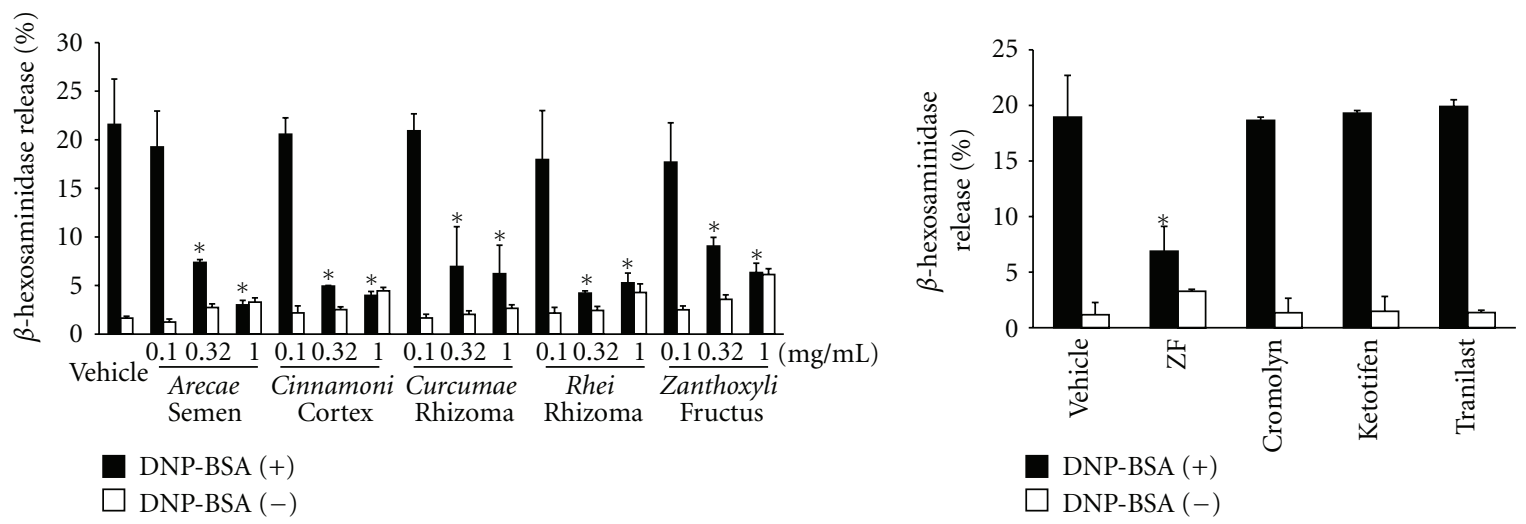

(b)

(c)

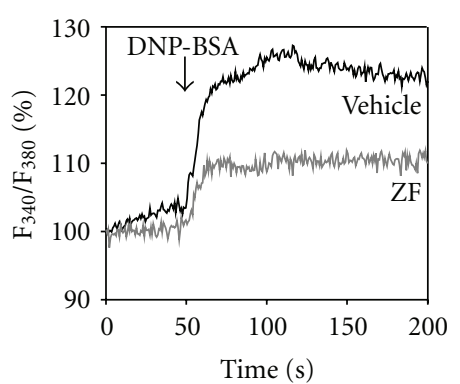

(d)

FIgure 1: Inhibitory effect of the water extracts of Arecae Semen, Cinnamoni Cortex, Curcumae Rhizoma, Rhei Rhizoma, and Zanthoxyli Fructus on degranulation that was induced by antigens in the RBL-2H3 cells. (a) The time scheme for the degranulation assay. (b) RBL$2 \mathrm{H} 3$ cells that were sensitized with $0.5 \mu \mathrm{g} / \mathrm{mL}$ anti-DNP IgE $(24 \mathrm{~h})$ were incubated with herbal medicine extracts for $30 \mathrm{~min}$. The cells were stimulated with (filled) or without (open) $100 \mathrm{ng} / \mathrm{mL}$ DNP-BSA for $1 \mathrm{~h}$, and $\beta$-hexosaminidase release was determined. (c) The inhibitory effect of antiallergic drugs $(10 \mu \mathrm{M})$ on DNP-BSA-induced degranulation was examined. The data are expressed as the mean \pm SD $(n=3$; B, C). ${ }^{*} P<0.05$ compared with the vehicle (b, c). (d) The effect of ZF $(0.32 \mathrm{mg} / \mathrm{mL})$ treatment on the increase of $\left[\mathrm{Ca}^{2+}\right]_{i}$ that was induced DNP-BSA. The RBL-2H3 cells that were sensitized with IgE were labeled with Fura-2 AM and treated with ZF or vehicle for 30 min. The $\mathrm{Ca}^{2+}$-mobilization was determined after stimulation with DNP-BSA using F4500. The data are representative of at least three independent experiments.

Zanthoxyli Fructus $(\geq 0.1 \mathrm{mg} / \mathrm{mL})$ inhibited the stimulated degranulation in a dose-dependent manner (Figure 1(b)). In contrast, none of the clinically available antiallergic drugs $(10 \mu \mathrm{M})$, cromolyn, ketotifen and tranilast, which are known to be connective tissue mast cell stabilizers, inhibited the degranulation (Figure 1(c)).

In an in vivo preliminary study, ZF $(500 \mathrm{mg} / \mathrm{kg}$ body weight) displayed the most potent inhibitory effect of the five extracts that were examined in our FA model (data not shown). Therefore, we selected ZF for further study.

The mobilization of intracellular calcium is essential for degranulation and cytokine production in mast cells. As shown in Figure 1(d), ZF attenuated the DNP-BSA-induced $\left[\mathrm{Ca}^{2+}\right]_{i}$ elevation in RBL-2H3 cells. In addition, ZF did not alter FceRI surface expression in RBL-2H3 cells (the expression was $96.3 \%$ of that of nontreated RBL-2H3), which indicates that ZF inhibits signals downstream of FceRI crosslinking.

Additionally, we examined the inhibitory effects of ZF constituents hydroxy- $\alpha$-sanshool, limonene, 3-O-caffeoylquinic acid, catechin, hyperine, and epicatechin $(1,10$, and $100 \mu \mathrm{M})$. Individually, hydroxyl- $\alpha$-sanshool, epicatechin, catechin, and hyperine slightly attenuated the degranulation only at the highest concentration $(100 \mu \mathrm{M})$ (Table 1). 
TABLE 1: The inhibitory activity of ZF components $(100 \mu \mathrm{M})$ on antigen-induced degranulation. The data are expressed as the mean $\pm \mathrm{SD}(n=3)$.

\begin{tabular}{lc}
\hline Compounds & Inhibition of degranulation (\%) \\
\hline Hydroxy- $\alpha$-sanshool & $21.1 \pm 11.9$ \\
Epicatechin & $15.7 \pm 7.1$ \\
Catechin & $13.0 \pm 4.8$ \\
Hyperoside & $7.7 \pm 5.2$ \\
Limonene & $-11.4 \pm 9.9$ \\
3-O-Caffeoylqunic acid & $-13.3 \pm 7.7$ \\
\hline
\end{tabular}

3.2. ZF Inhibits Antigen-Induced Activities in mBMMCs. In a dose-dependent manner, ZF significantly inhibited the degranulation of the mBMMCs that were induced with DNP-BSA (Figure 2(b)) without detectably affecting the viability of the mBMMCs (Figure 2(c)). As shown in Figure $2(\mathrm{~d})$, mRNA expression of TNF- $\alpha$, IL-4, and IL-13 was extremely enhanced by DNP-BSA. ZF $(0.32 \mathrm{mg} / \mathrm{mL})$ significantly suppressed the increased expression of TNF$\alpha$, IL-4, and IL-13. In contrast, the expression of these genes was not affected by ZF in the mBMMCs that were not stimulated with DNP-BSA (unactivated mBMMCs). In addition, ZF attenuated the DNP-BSA-induced $\left[\mathrm{Ca}^{2+}\right]_{i}$ increases (Figure 2(e)).

3.3. ZF Reduces Sphk1 mRNA Expression in AntigenStimulated mBMMCs. To investigate the pharmacological mechanism that is responsible for the inhibitory effect of ZF on mBMMCs, we examined the global mRNA expression profiles of normal mBMMCs, DNP-BSA-stimulated mBMMCs (activated mBMMCs), and ZF-pretreated activated mBMMCs (ZF mBMMCs) using an Affymetrix Mouse GeneChip Array. The expression levels of 49 genes were elevated $>2$-fold higher in the activated mBMMCs when compared to the normal mBMMCs, and they were decreased by $>50 \%$ in the ZF mBMMCs when compared to the activated mBMMCs. In contrast, the expression levels of 6 genes were decreased by $>50 \%$ in the activated mBMMCs when compared to the normal mBMMCs, and they were elevated $>2$-fold higher in the ZF mBMMCs when compared to the activated mBMMCs (Table 2). Interestingly, the expression of Sphk1, which plays an important role in antigen-induced degranulation [18-20], was induced approximately 5.7fold in the activated mBMMCs when compared with the normal mBMMCs. The ZF pretreatment greatly reduced the expression of Sphk1 to $16 \%$ of the expression level in the activated mBMMCs, whereas the DNP-BSA stimulation did not alter Sphk2 expression when compared with that in the normal mBMMCs (1.35-fold relative to the normal mBMMCs).

Furthermore, we quantitatively assessed the suppressive effect of ZF on Sphk1 mRNA expression using real-time PCR. As shown in Figure 3, the Sphk1 mRNA expression level in the activated mBMMCs was markedly enhanced 10.2-fold relative to the unactivated mBMMCs. The induction was dramatically reduced to approximately $20 \%$ in the
ZF mBMMCs. In contrast, the Sphk1 mRNA expression was not affected by ZF in the unactivated mBMMCs.

To clarify the involvement of Sphk1 in the degranulation of mucosal mast cells, we examined the effect of DMS, which is a specific Sphk inhibitor, on the antigen-induced degranulation in mBMMCs. DMS $(10 \mu \mathrm{M})$ significantly suppressed the release of $\beta$-hexosaminidase (Figure 4).

3.4. ZF Inhibits Calcium Ionophore-Induced Degranulation. To investigate the pharmacological profile of ZF on mucosal mast cell activation, we examined the effect of $\mathrm{ZF}$ on the $\left[\mathrm{Ca}^{2+}\right]_{i}$ increases and $\beta$-hexosaminidase release induced by the calcium ionophore A23187. The ZF treatment diminished the $\left[\mathrm{Ca}^{2+}\right]_{i}$ increases in RBL-2H3 cells (Figure 5(b)). In addition, ZF significantly inhibited A23187-induced degranulation in both RBL-2H3 cells and mBMMCs (Figures 5(c), 5(d)). Moreover, the calcineurin inhibitor cyclosporin A $(1 \mu \mathrm{M})$, the calmodulin antagonist W-7 $(32 \mu \mathrm{M})$, and the $\mathrm{Ca}^{2+} /$ calmodulin-dependent protein kinase II inhibitor KN-93 $(32 \mu \mathrm{M})$ inhibited A23187-induced degranulation in mBMMCs to a similar extent as ZF, which indicates that A23187 induces degranulation via both calcineurin- and calmodulin-dependent pathways in mBMMCs (Figure 5(d)). In contrast, DMS $(10 \mu \mathrm{M})$ did not affect A23187-induced degranulation in mBMMCs (Figure 5(d)). Furthermore, when the mBMMCs were stimulated with the calcium ionophore A23187 (instead of anti-DNP IgE and DNP-BSA) and examined with the Affymetrix Mouse Genechip Array, the expression of Sphk1 was not altered (data not shown).

\subsection{ZF Suppresses Allergic Symptoms in the Murine FA Model.} In OVA-challenged mice (FA mice), allergic diarrhea began to occur after the third oral OVA challenge (Figure 6(a)). The administration of ZF $(320 \mathrm{mg} / \mathrm{kg})$ significantly reduced the incidence of OVA-induced diarrhea, and the incidence of diarrhea was decreased to approximately $40 \%$ after the sixth OVA challenge. As shown in Figure 6(b), the administration of DMS $(1 \mathrm{mg} / \mathrm{kg})$ likewise significantly reduced the incidence of diarrhea. Furthermore, the number of mucosal mast cells that were observed by immunohistochemistry with mMCP-1 antibody dramatically increased in the proximal colons of FA mice compared with the number in normal mice, which is consistent with our previous paper [6]. ZF and DMS dramatically decreased the number of infiltrating mucosal mast cells in the proximal colons of the FA mice (Figure 6(c)). In addition, as shown in Figure 6(d), ZF repressed the mRNA expression of IL-4 and Sphk1 in the proximal colons of the FA mice.

\section{Discussion}

In this study, we have demonstrated in vitro and in vivo that ZF inhibited FceRI cross-linking-induced mucosal mast cell activation; this inhibition was primarily achieved via the suppression of Sphk1 mRNA expression, and Sphk1 plays a key role in FceRI-mediated immune responses in mucosal mast cells. Furthermore, ZF suppressed the calcium ionophore-induced degranulation, which could not 


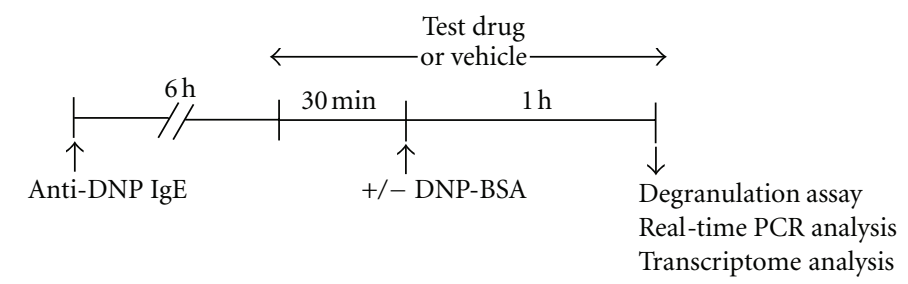

(a)

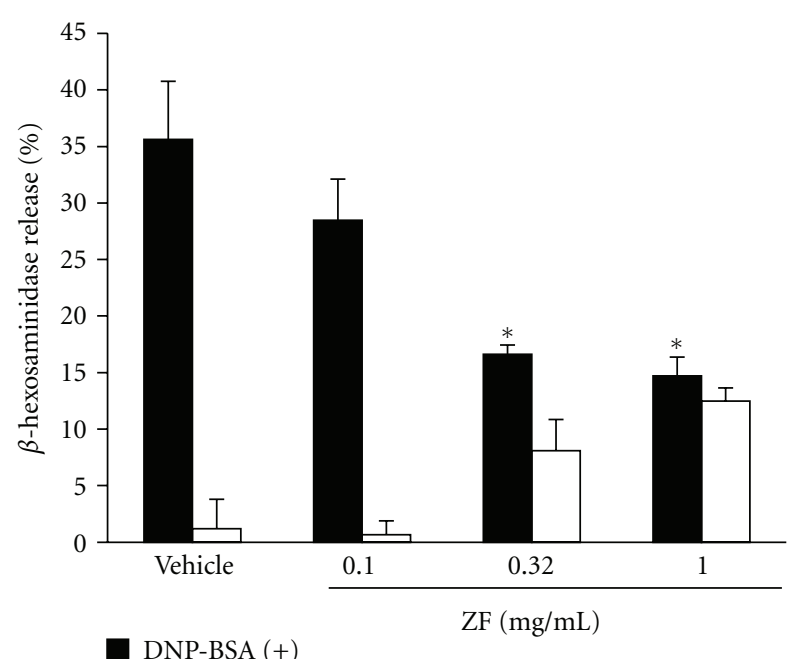

$\square$ DNP-BSA (-)

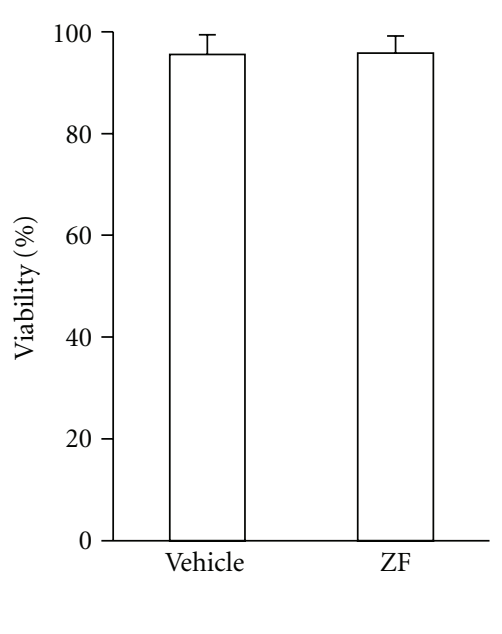

(c)
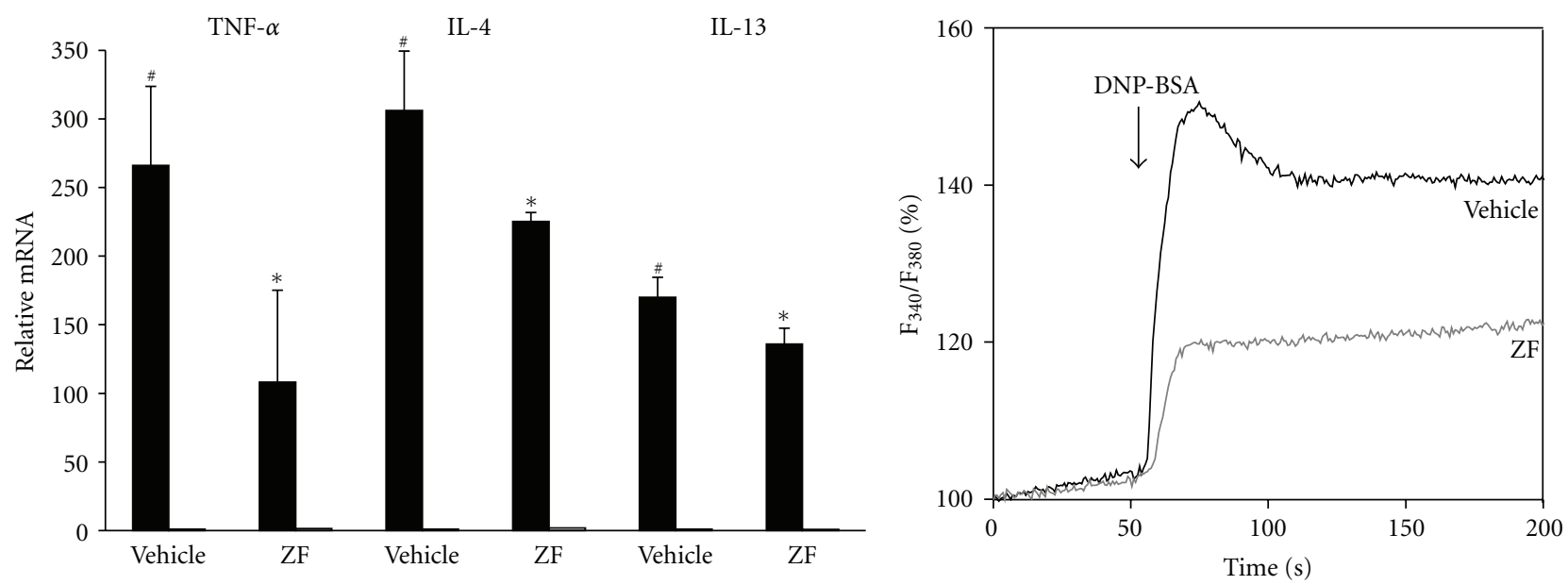

$\operatorname{DNP}-\mathrm{BSA}(+)$

DNP-BSA (-)

(d)

(e)

FIGURE 2: The effect of ZF $(0.32 \mathrm{mg} / \mathrm{mL})$ on degranulation, cytokine levels, and $\left[\mathrm{Ca}^{2+}\right]_{i}$ elevation of the mBMMCs that were stimulated with DNP-BSA. (a) The time scheme for the degranulation assay, real-time PCR analysis, and transcriptome analysis. (b) The mBMMCs that were sensitized with $1.5 \mu \mathrm{g} / \mathrm{mL}$ anti-DNP IgE $(6 \mathrm{~h})$ were incubated with ZF for $30 \mathrm{~min}$. The cells were stimulated with (filled) or without (open) DNP-BSA $(1 \mathrm{~h})$, and the $\beta$-hexosaminidase release was determined. (c) The mBMMCs were pretreated with $\mathrm{ZF}(0.32 \mathrm{mg} / \mathrm{mL})$ for $90 \mathrm{~min}$ and stained with PI; the viability was analyzed using the FACS Calibur system. (d) The sensitized mBMMCs were incubated with ZF $(0.32 \mathrm{mg} / \mathrm{mL})$ or vehicle for $30 \mathrm{~min}$ and then stimulated with DNP-BSA for $1 \mathrm{~h}$, and the total RNA was extracted. The mRNA levels of TNF- $\alpha$, IL-4, and IL-13 were analyzed by real-time PCR. The results are expressed as the relative ratio to the vehicle-treated mBMMCs without DNP-BSA stimulation. The data are expressed as the mean $\pm \mathrm{SD}(n=3-4 ; \mathrm{b}, \mathrm{c}, \mathrm{d}) .{ }^{*} P<0.05$ compared with DNP-BSA ( $)$ (d), ${ }^{*} P<0.05$ compared with the vehicle (b, d). (e) The sensitized mBMMCs were labeled with Fura-2 AM for 30 min and incubated with ZF or vehicle for $30 \mathrm{~min}$. $\mathrm{Ca}^{2+}$-mobilization was determined following stimulation with DNP-BSA. The data are representative of at least three independent experiments. 
TABLE 2: List of genes selected by microarray analysis. The fold-change $\log _{2}$ ratio was calculated as the $\log _{2}$ ratio of the expression level in the activated mBMMCs compared to the expression in the normal mBMMCs or as the $\log _{2}$ ratio of the expression level in the ZF mBMMCs compared to that in the activated mBMMCs. (a) Upregulation ( $>2$ fold) of genes by DNP-BSA stimulation and downregulation $(>2$ fold) after ZF pretreatment. (b) Downregulation ( $>2$ fold) of genes by DNP-BSA stimulation and upregulation ( $>2$ fold) after ZF pretreatment.

\begin{tabular}{|c|c|c|c|}
\hline \multirow{2}{*}{ Gene name } & \multirow{2}{*}{ Gene description } & \multicolumn{2}{|c|}{ Fold-change $\log _{2}$ ratio } \\
\hline & & $\begin{array}{l}\text { IgE }+ \text { DNP/ } \\
\text { Normal }\end{array}$ & $\begin{array}{c}\mathrm{ZF} / \\
\mathrm{IgE}+\mathrm{DNP}\end{array}$ \\
\hline \multicolumn{4}{|c|}{ (a) } \\
\hline Tnip3 & TNFAIP3 interacting protein 3 & 4.47 & -3.36 \\
\hline Sphk1 & Sphingosine kinase 1 & 2.50 & -2.65 \\
\hline Chacl & ChaC, cation transport regulator-like 1 (E. coli) & 1.80 & -2.40 \\
\hline Trib1 & Tribbles homolog 1 (Drosophila) & 3.21 & -2.39 \\
\hline Uhrf1bp1l & UHRF1 (ICBP90) binding protein 1-like & 1.82 & -2.23 \\
\hline Car2 & Carbonic anhydrase 2 & 2.16 & -1.86 \\
\hline Socs3 & Suppressor of cytokine signaling 3 & 1.89 & -1.82 \\
\hline Sema7a & $\begin{array}{l}\text { Sema domain, immunoglobulin domain (Ig), and GPI } \\
\text { membrane anchor, (semaphorin) 7A }\end{array}$ & 2.25 & -1.77 \\
\hline Fermt2 & Fermitin family homolog 2 (Drosophila) & 2.81 & -1.75 \\
\hline Zfp57 & Zinc finger protein 57 & 1.90 & -1.71 \\
\hline Klf9|Gm9971 & Kruppel-like factor 9 | predicted gene 9971 & 1.42 & -1.68 \\
\hline Mustn1 & Musculoskeletal, embryonic nuclear protein 1 & 1.57 & -1.64 \\
\hline Tnfsf8 & Tumor necrosis factor (ligand) superfamily, member 8 & 2.48 & -1.64 \\
\hline Gimap5 & GTPase, IMAP family member 5 & 1.41 & -1.61 \\
\hline Dusp18 & Dual-specificity phosphatase 18 & 1.08 & -1.58 \\
\hline Slco4al & Solute carrier organic anion transporter family, member 4a1 & 2.25 & -1.57 \\
\hline Fhl2 & Four and a half LIM domains 2 & 1.06 & -1.56 \\
\hline Spry2 & Sprouty homolog 2 (Drosophila) & 2.64 & -1.53 \\
\hline A630033H20Rik & RIKEN cDNA A630033H20 gene & 2.34 & -1.52 \\
\hline Zc3h12a & Zinc finger $\mathrm{CCCH}$ type containing $12 \mathrm{~A}$ & 1.70 & -1.51 \\
\hline Nfkbia & $\begin{array}{l}\text { Nuclear factor of kappa light polypeptide gene enhancer in } \\
\text { B-cells inhibitor, alpha }\end{array}$ & 1.92 & -1.50 \\
\hline Il2 & Interleukin 2 & 1.91 & -1.50 \\
\hline Zc3h12c & Zinc finger $\mathrm{CCCH}$ type containing $12 \mathrm{C}$ & 2.28 & -1.47 \\
\hline Marcksl1 & MARCKS-like 1 & 2.88 & -1.42 \\
\hline Hbegf & Heparin-binding EGF-like growth factor & 4.90 & -1.41 \\
\hline Csf2 & Colony stimulating factor 2 (granulocyte macrophage) & 5.30 & -1.41 \\
\hline Erf & Ets2 repressor factor & 2.10 & -1.40 \\
\hline Kcnk5 & Potassium channel, subfamily K, member 5 & 1.13 & -1.38 \\
\hline Mmd & Monocyte to macrophage differentiation associated & 2.05 & -1.37 \\
\hline Phldal & Pleckstrin homology-like domain, family A, member 1 & 3.10 & -1.32 \\
\hline Zc3h12c & Zinc finger $\mathrm{CCCH}$ type containing $12 \mathrm{C}$ & 2.26 & -1.31 \\
\hline Rilpl2 & Rab interacting lysosomal protein-like 2 & 1.48 & -1.31 \\
\hline Faah & Fatty acid amide hydrolase & 2.35 & -1.29 \\
\hline Fst|Thrap3 & Follistatin | thyroid-hormone-receptor-associated protein 3 & 1.67 & -1.19 \\
\hline Insig1 & Insulin-induced gene 1 & 1.65 & -1.19 \\
\hline Spry1 & Sprouty homolog 1 (Drosophila) & 4.36 & -1.19 \\
\hline Pde12 & Phosphodiesterase 12 & 1.29 & -1.19 \\
\hline Rc3h1 & RING CCCH $(\mathrm{C} 3 \mathrm{H})$ domains 1 & 1.13 & -1.18 \\
\hline Dusp2 & Dual-specificity phosphatase 2 & 2.15 & -1.15 \\
\hline
\end{tabular}


TABle 2: Continued.

\begin{tabular}{|c|c|c|c|}
\hline \multirow{2}{*}{ Gene name } & \multirow{2}{*}{ Gene description } & \multicolumn{2}{|c|}{ Fold-change $\log _{2}$ ratio } \\
\hline & & $\begin{array}{l}\text { IgE }+ \text { DNP/ } \\
\text { Normal }\end{array}$ & $\begin{array}{c}\mathrm{ZF} / \\
\operatorname{IgE}+\mathrm{DNP}\end{array}$ \\
\hline F3 & Coagulation factor III & 1.16 & -1.13 \\
\hline Eda2r & Ectodysplasin A2 receptor & 1.65 & -1.11 \\
\hline Prrg4 & Proline-rich Gla (G-carboxyglutamic acid) 4 (transmembrane) & 1.95 & -1.11 \\
\hline Traf6 & TNF receptor-associated factor 6 & 1.03 & -1.08 \\
\hline Peli1 & Pellino 1 & 1.48 & -1.07 \\
\hline $\mathrm{Cxcl} 2$ & Chemokine (C-X-C motif) ligand 2 & 3.91 & -1.04 \\
\hline Ptger4 & Prostaglandin E receptor 4 (subtype EP4) & 1.06 & -1.03 \\
\hline Siah2 & Seven in absentia 2 & 1.20 & -1.02 \\
\hline Chka & Choline kinase alpha & 1.58 & -1.01 \\
\hline \multirow[t]{2}{*}{ Ehd4 } & EH-domain containing 4 & 1.10 & -1.01 \\
\hline & (b) & & \\
\hline $\mathrm{Cbfa} 2 \mathrm{t} 3$ & $\begin{array}{l}\text { Core-binding factor, runt domain, alpha subunit } 2 \text {, translocated } \\
\text { to } 3 \text { (human) }\end{array}$ & -1.59 & 1.71 \\
\hline ATP6|Gm10925 & ATP synthase F0 subunit 6 | predicted gene 10925 & -1.20 & 2.01 \\
\hline Nynrin & NYN domain and retroviral integrase containing & -1.11 & 1.00 \\
\hline Hist1h1c & Histone cluster $1, \mathrm{H} 1 \mathrm{c}$ & -1.01 & 1.15 \\
\hline Arrdc3 & Arrestin domain containing 3 & -1.10 & 1.36 \\
\hline Gfilb & Growth-factor-independent $1 \mathrm{~B}$ & -1.52 & 1.40 \\
\hline
\end{tabular}

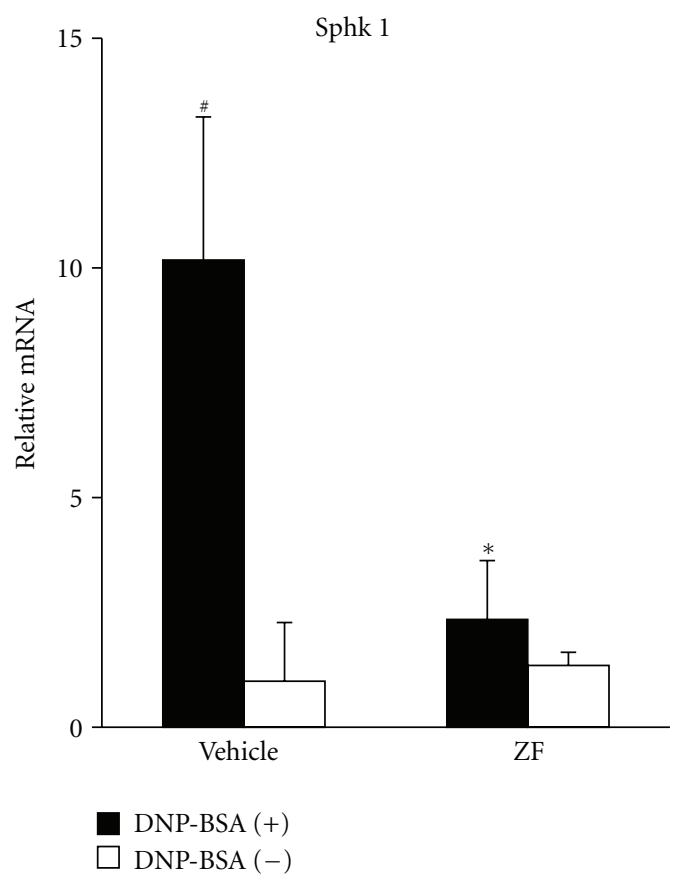

FIGURE 3: The effect of ZF $(0.32 \mathrm{mg} / \mathrm{mL})$ on the mRNA expression levels of Sphk1. The sensitized mBMMCs were incubated with ZF or vehicle for $30 \mathrm{~min}$ and were stimulated with (filled) or without (open) DNP-BSA. The mRNA levels of Sphk1 were analyzed by real-time PCR. The results are expressed as the relative ratio to the vehicle-treated $\mathrm{mBMMCs}$ without DNP-BSA stimulation. The data are expressed as the mean $\pm \mathrm{SD}(n=3) .{ }^{\#} P<0.05$ compared with DNP-BSA $(-),{ }^{*} P<0.05$ compared with the vehicle. be suppressed by an Sphk1 inhibitor. Therefore, the present results suggest that $\mathrm{ZF}$ could be utilized for the development of a novel, potent anti-FA agent.

4.1. Inhibitory Effect of ZF on Antigen-Induced Mucosal Mast Cell Activation In Vitro. Mast cells are key players in various allergic responses, and mucosal mast cells have been shown to play pivotal roles in gastrointestinal hypersensitivity [68]. They respond to both IgE-dependent (antigen) and IgEindependent (such as bacterial toxins and neurotransmitters) stimulation and release a wide variety of bioactive mediators into adjacent tissues [21].

Although the available mast cell stabilizers did not affect degranulation in RBL-2H3 cells as well as mBMMCs, ZF inhibited antigen-induced degranulation in mBMMCs and RBL-2H3 cells. Mast cells generate and release proinflammatory and Th2-related cytokines, including TNF- $\alpha$, IL4 , and IL-13, in response to various stimuli [3]. TNF- $\alpha$ is largely responsible for allergic inflammation, and IL-4, and IL-13 are necessary for the development of Th2 immune responses and the induction of IgE class switching [4]. ZF significantly inhibited the mRNA expression of these cytokines in the mBMMCs. Lee et al. have recently reported in a connective-tissue mast cell model that glycoproteins in the Zanthoxyli Fructus have an inhibitory effect on the release of histamine and $\beta$-hexosaminidase in the compound 48/80-treated human mast cells [16]. In mucosal-type mast cells, ZF displayed potent inhibitory effects on degranulation and proinflammatory- and Th2-related cytokine production, and ZF suppressed the increase of $\left[\mathrm{Ca}^{2+}\right]_{i}$ that was triggered by antigens in RBL-2H3 cells and mBMMCs. These results 


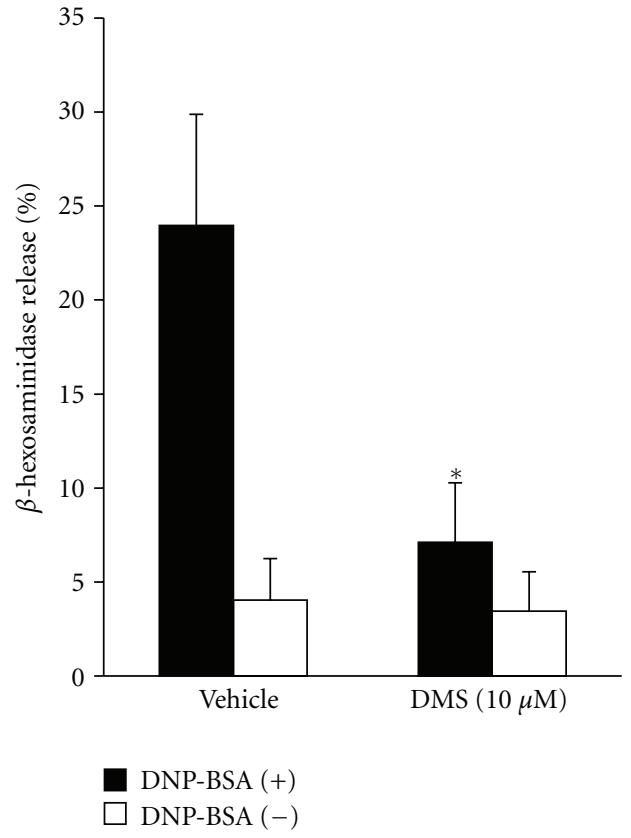

FIgURE 4: The inhibitory effect of DMS on the degranulation of $\mathrm{mBMMCs}$ that were induced by DNP-BSA. The sensitized mBMMCs were pretreated with $10 \mu \mathrm{M}$ DMS for $30 \mathrm{~min}$ prior to DNP-BSA stimulation. The data are expressed as the mean \pm SD $(n=4) .{ }^{*} P<0.05$ compared with the vehicle.

suggest that ZF inactivates mucosal mast cells by suppressing $\left[\mathrm{Ca}^{2+}\right]_{i}$

Individually, the constituents of ZF that were tested here did not significantly inhibit antigen-induced degranulation in RBL-2H3 cells. One possible explanation for this result is that the inhibitory effect of ZF on mast cells is related to the additive/synergistic effects of these and other constituents in $\mathrm{ZF}$. However, further studies on the active constituents of ZF will be required to fully explain the inhibitory effect of $\mathrm{ZF}$.

4.2. Suppression of Sphk1 mRNA Expression by ZF and the Pathophysiological Role of Sphk1 in Mucosal Mast Cells In Vitro. To investigate the mechanism underlying the inhibitory effect of ZF on mucosal mast cell activation, we performed global transcriptional profiling of mBMMCs by DNA microarray. We found that the expression level of Sphk1 mRNA was increased in the antigen-stimulated mBMMCs and decreased following ZF treatment. The stimulation of mast cells by antigens induces two mammalian Sphks (Sphk1 and Sphk2) to generate sphingosine 1-phosphate (S1P). S1P has been demonstrated to function intracellularly as a second messenger for the regulation of cell survival, cell proliferation, and intracellular $\mathrm{Ca}^{2+}$ mobilization $[22,23]$. A recent study shows that Sphk1 but not Sphk2 plays a critical role in the antigen-induced $\left[\mathrm{Ca}^{2+}\right]_{i}$ elevation, degranulation, and cytokine production in connective-tissue type BMMCs [18]. Furthermore, antigeninduced degranulation is suppressed by the deletion of Sphk1 in RBL-2H3 cells and human mast cells $[19,20]$.
In the present study, our results revealed that the Sphk inhibitor DMS significantly suppressed antigen-induced degranulation in mBMMCs. Thus, Sphk1 is a determinant of the responsiveness to the cross-linking of FceRI with antigen in mucosal mast cells as well as connective-tissue mast cells. Furthermore, ZF decreased the antigen-induced elevation of $\left[\mathrm{Ca}^{2+}\right]_{i}$ through the suppression of antigeninduced enhancement of Sphk1 mRNA expression in vitro. Therefore, Sphk1 may be a new therapeutic target for diseases that are caused by both types of mast cells; ZF may provide an opportunity to develop a novel therapeutic strategy for the treatment of FA. To date, Sphk inhibitor DMS and the S1P receptor modulator FYT720 have been developed, while there is no information about drugs that suppress the expression of Sphk1. Taken together, these data suggest that ZF may provide a prototype for therapeutic drugs for the treatment of various allergic diseases, particularly FA.

4.3. Sphk1-Independent Mechanism Underlying the Inhibitory Effect of ZF on Mucosal Mast Cells In Vitro. We found that the calcium ionophore A23187 did not alter Sphk1 mRNA expression in mBMMCs using a transcriptome analysis (our unpublished data), and DMS did not inhibit A23187induced degranulation in mBMMCs, which is consistent with previous reports. Both the DMS treatment and Sphk1 knock-down fail to affect ionomycin-induced degranulation in RBL-2H3 cells or connective-tissue-type BMMCs [18, 19]. Taken together, these data suggest that Sphk1 acts at the upstream of the calcium signaling pathway in mast cells. In contrast, ZF suppressed A23187-induced degranulation and $\left[\mathrm{Ca}^{2+}\right]_{i}$ elevation in mucosal-type mast cells. Furthermore, in mBMMCs, the calcineurin inhibitor cyclosporin A, the calmodulin antagonist $\mathrm{W}-7$, and the $\mathrm{Ca}^{2+} /$ calmodulindependent protein kinase II inhibitor KN-93 suppressed A23187-induced degranulation to a similar extent as ZF, which is consistent with previous reports $[24,25]$. These results indicate that $\mathrm{A} 23187$ induces degranulation via both calcineurin- and calmodulin-dependent pathways in mast cells. Taken together, these data suggest that ZF suppresses the activation of mast cells by blocking calcium influx with or without inhibiting calcineurin- and calmodulindependent pathways in mast cells. Therefore, our results indicate that ZF suppresses not only antigen-induced Sphk1 expression, but also critical molecules in the calcium influx pathway. Additional studies will be required to understand this inhibitory mechanism.

4.4. Therapeutic Effect of ZF and Inhibition of the Sphk1 Pathway in the Murine FA Model In Vivo. The oral administration of ZF suppressed the occurrence of allergic diarrhea and decreased the number of colonic mucosal mast cells in our FA model. We showed that the administration of ZF downregulated the mRNA expression of IL- 4 in the proximal colons of FA mice, which suggests that ZF suppressed the Th2-polarized cytokine profile in the proximal colons of FA mice. In addition, ZF inhibited the expression of Sphk1 mRNA in the proximal colons of FA mice. Furthermore, in the present study, DMS likewise reduced the occurrence 


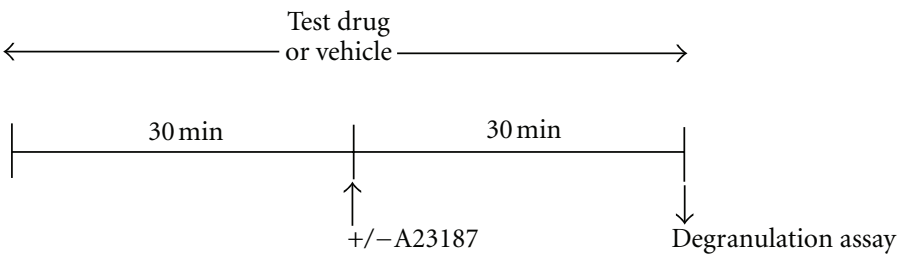

(a)

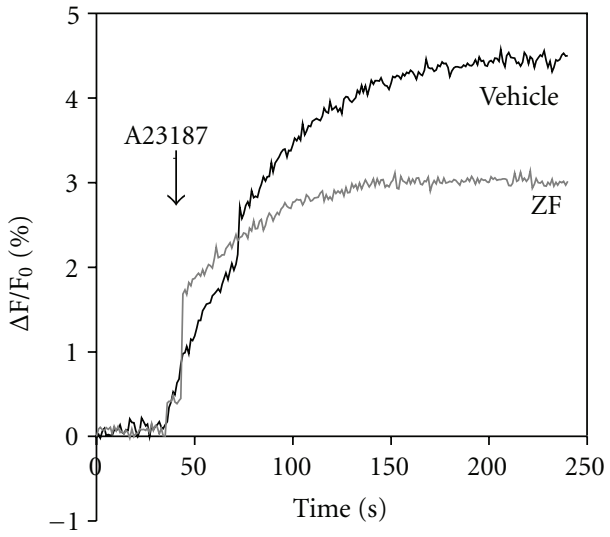

(b)

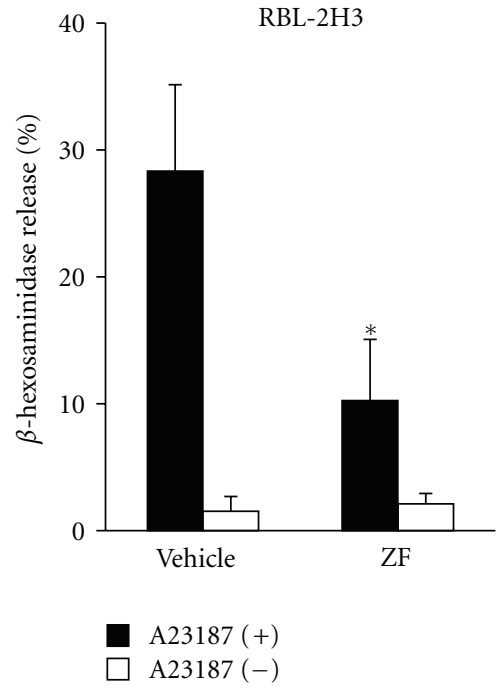

(c)

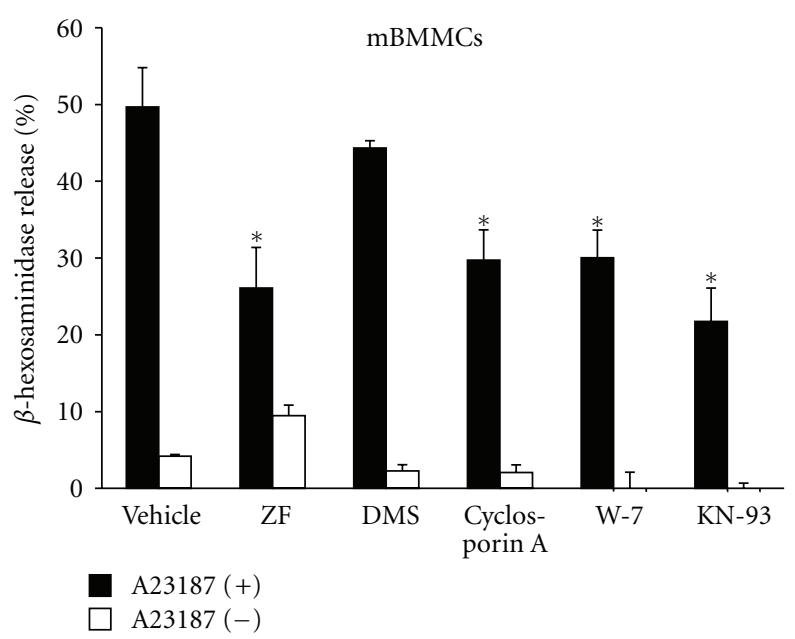

(d)

Figure 5: The effect of ZF $(0.32 \mathrm{mg} / \mathrm{mL})$ treatment on A23187-induced $\left[\mathrm{Ca}^{2+}\right]_{i}$ elevation and degranulation. (a) The time scheme for the degranulation assay. (b) RBL-2H3 cells were labeled with Fluo-3 AM and incubated with ZF or vehicle for 30 min. The cells were stimulated with $25 \mu \mathrm{M}$ A23187 and monitored by calcium imaging. The data are representative of at least three independent experiments. (c) The RBL$2 \mathrm{H} 3$ cells were incubated with $\mathrm{ZF}$ or vehicle for $30 \mathrm{~min}$, the cells were stimulated with (filled) or without (open) A23187 for $30 \mathrm{~min}$, and $\beta$-hexosaminidase release was determined. (d) The mBMMCs were incubated with ZF $(0.32 \mathrm{mg} / \mathrm{mL})$, DMS ( $10 \mu \mathrm{M})$, cyclosporin A ( $1 \mu \mathrm{M})$, $\mathrm{W}-7(32 \mu \mathrm{M}), \mathrm{KN}-93(32 \mu \mathrm{M})$, or vehicle for $30 \mathrm{~min}$, and the cells were stimulated with $25 \mu \mathrm{M} \mathrm{A} 23187$ for 30 min. $\beta$-hexosaminidase release was determined. The data are expressed as the mean $\pm \mathrm{SD}(n=4 ; \mathrm{c}, \mathrm{d}) .{ }^{*} P<0.05$ compared with the vehicle (c, d).

of allergic diarrhea and the number of mucosal mast cells in the proximal colons of FA mice. Similarly, DMS exerts an inhibitory effect on the OVA-induced pulmonary inflammatory responses in a murine model of allergic asthma [26]. It is generally accepted that the activation and degranulation of mast cells that are induced by antigens and the migration of mast cells toward antigens are important pathogenic mechanisms in allergic diseases. In the present study, we demonstrated that the number of mucosal mast cells was greatly increased in the proximal colons of FA mice, and the increase was reduced following the treatment with ZF or DMS. However, the mechanism by which these mucosal mast cells migrate to sites of allergy reaction in the colon is not fully understood. It has been reported that DMS can inhibit the movement of RBL-2H3 cells toward antigens [19]. Furthermore, the downregulation of Sphk1 expression using small interfering RNA completely blocks the migration toward antigens in RBL-2H3 cells [19] and human mast cells [20], whereas the downregulation of Sphk2 has no effect $[19,20]$. Thus, these findings suggest that ZF downregulates Sphk1 expression and thereby suppresses both the activation of mast cells that are induced by the antigens and the migration of mast cells toward the antigens. Furthermore, Zanthoxyli Fructus is one of the herbal constituents in FAHF1 and FAHF- 2 which show inhibition of systemic anaphylaxis and suppression of histamine release in a murine model of food allergy $[13,14]$. In particular, FAHF-2 has inhibitory effects on peripheral blood basophils from patients with food 


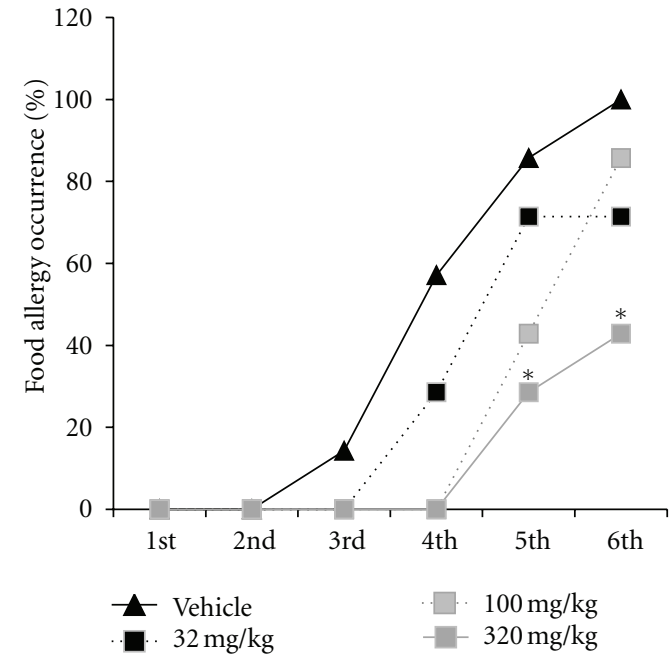

(a)
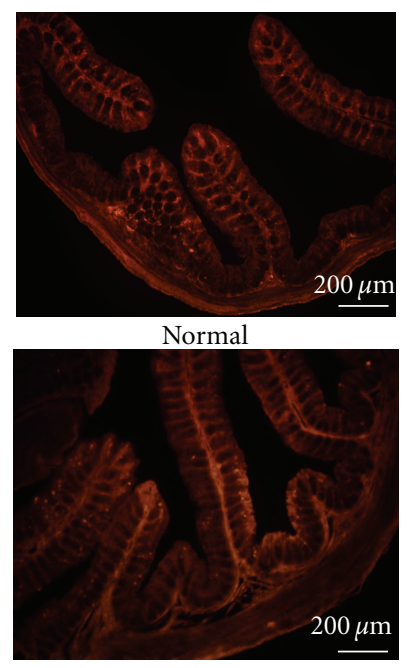

ZF
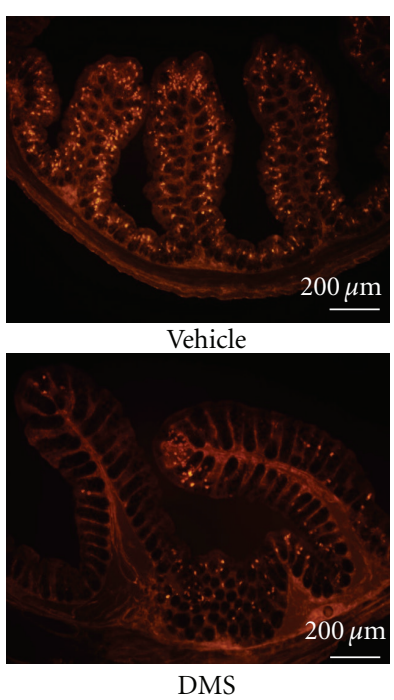

(c)

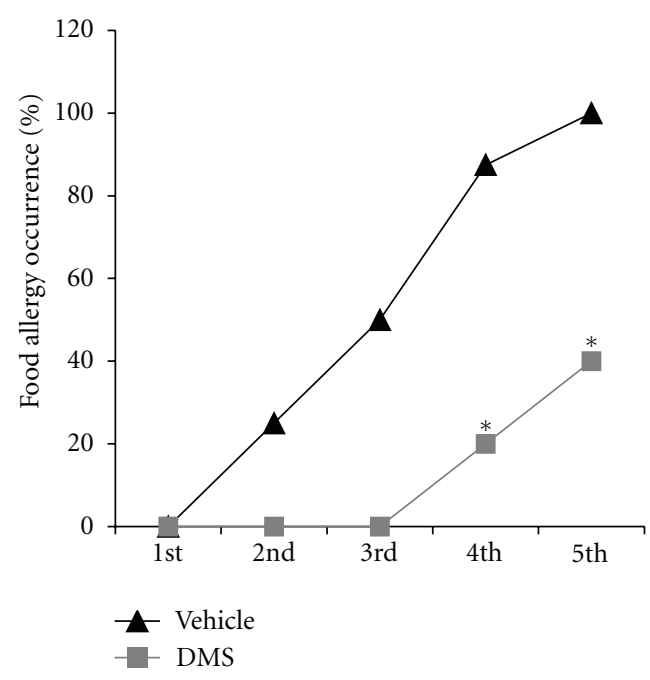

(b)

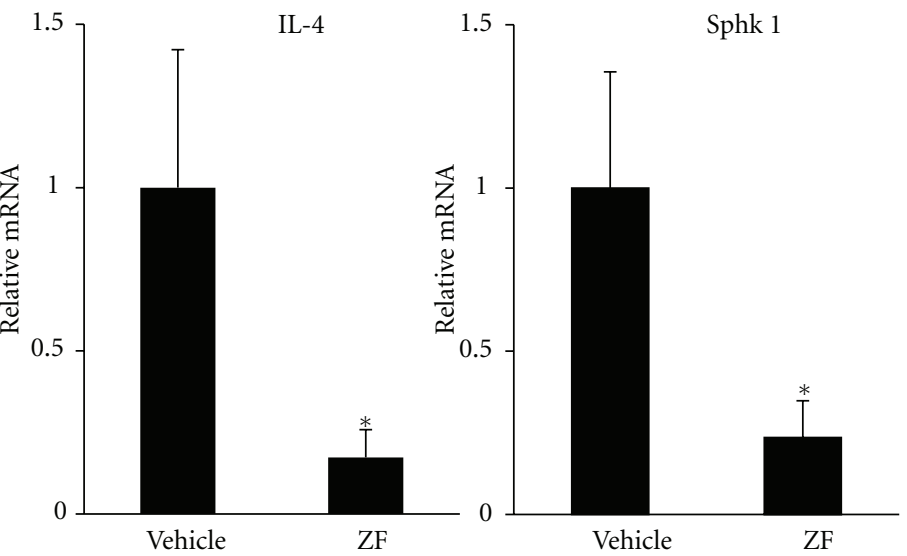

(d)

FIGURE 6: The effect of ZF and DMS on the development of FA in vivo. (a) The induction of allergic diarrhea was compared between the vehicle- and ZF-treated groups. ZF was orally administered during the induction of allergic diarrhea by OVA oral challenge as described in the Materials and Methods section $(n=8)$. (b) DMS $(1 \mathrm{mg} / \mathrm{kg})$ suppressed the incidence of allergic diarrhea $(n=5-8)$. (c) The proximal colons of the vehicle, ZF $(320 \mathrm{mg} / \mathrm{kg})$, and DMS $(1 \mathrm{mg} / \mathrm{kg})$ treated mice after oral challenge with OVA were stained with anti-mMCP1 antibody. The scale bar represents $200 \mu \mathrm{m}$. (d) The expression levels of IL- 4 and sphk1 in the proximal colons were measured using real-time PCR. The results are expressed as the relative ratio to the proximal colons of the vehicle-treated FA mice. The data are expressed as the mean $\pm \mathrm{SD}$ $(n=5) .{ }^{*} P<0.05$ compared with the vehicle.

allergy [15]. These previous studies may further support the findings of this study that ZF may have a potential for food allergy treatment. Taken all together, it is suggested that ZF may provide a novel strategy for the treatment of FA via inhibition of the Sphk pathway.

Although the active compounds in ZF have not yet been identified, ZF provides novel insights into the development of a therapeutic drug against both Sphk1-dependent and independent mechanisms of FA that are closely related to the activity of mucosal mast cells. Furthermore, ZF or its active constituents may provide a novel prototype for antiallergic agents that act via the inhibition of Sphk1-dependent and independent pathways.

\section{Acknowledgments}

The authors would like to thank Dr. Syed Faisal Haider Zaidi (Department of Biological and Biomedical Sciences, Aga Khan University, Pakistan) for his kind assistance in the preparation of this paper and Dr. Tatsuo Katagiri (Department of Biology, University of Toyama, Japan) for his helpful 
discussion. This research was supported by a Grant-inAid for Scientific Research from the Ministry of Education, Culture, Sports, Science and Technology of Japan to M. Kadowaki (no. 21590760) and by the Knowledge Cluster Initiative Program (Second Stage) from the Ministry of Education, Culture, Sports, Science and Technology of Japan to M. Kadowaki.

\section{References}

[1] S. H. Sicherer and H. A. Sampson, "Food allergy," Journal of Allergy and Clinical Immunology, vol. 117, no. 2, pp. S470S475, 2006.

[2] H. S. Skolnick, M. K. Conover-Walker, C. B. Koerner, H. A. Sampson, W. Burks, and R. A. Wood, "The natural history of peanut allergy," Journal of Allergy and Clinical Immunology, vol. 107, no. 2, pp. 367-374, 2001.

[3] Y. A. Mekori and D. D. Metcalfe, "Mast cells in innate immunity," Immunological Reviews, vol. 173, pp. 131-140, 2000.

[4] J. Kalesnikoff and S. J. Galli, "New developments in mast cell biology," Nature Immunology, vol. 9, no. 11, pp. 1215-1223, 2008.

[5] M. F. Gurish and J. A. Boyce, "Mast cell growth, differentiation, and death," Clinical Reviews in Allergy and Immunology, vol. 22, no. 2, pp. 107-118, 2002.

[6] T. Yamamoto, K. Fujiwara, M. Yoshida et al., "Therapeutic effect of kakkonto in a mouse model of food allergy with gastrointestinal symptoms," International Archives of Allergy and Immunology, vol. 148, no. 3, pp. 175-185, 2009.

[7] T. Kodama, T. Yamamoto, K. Fujiwara, M. Yoshida, S. Koyasu, and M. Kadowaki, "Pathological role of mucosal mast cells and CD4+ T cells for the induction of food allergy in mice," Gastroenterology, vol. 132, p. 392, 2007.

[8] N. Kageyama-Yahara, Y. Suehiro, F. Maeda et al., "Pentagalloylglucose down-regulates mast cell surface FceRI expression in vitro and in vivo," FEBS Letters, vol. 584, no. 1, pp. 111-118, 2010.

[9] N. Kageyama-Yahara, Y. Suehiro, T. Yamamoto, and M. Kadowaki, "IgE-induced degranulation of mucosal mast cells is negatively regulated via nicotinic acetylcholine receptors," Biochemical and Biophysical Research Communications, vol. 377, no. 1, pp. 321-325, 2008.

[10] F. L. Pearce, A. D. Befus, and J. Bienenstock, "Mucosal mast cells-III. Effect of quercetin and other flavonoids on antigeninduced histamine secretion from rat intestinal mast cells," Journal of Allergy and Clinical Immunology, vol. 73, no. 6, pp. 819-823, 1984.

[11] R. Moriez, M. Leveque, C. Salvador-Cartier et al., "Mucosal mast cell proteases are involved in colonic permeability alterations and subsequent bacterial translocation in endotoxemic rats," Shock, vol. 28, no. 1, pp. 118-124, 2007.

[12] X. M. Li, “Traditional Chinese herbal remedies for asthma and food allergy," Journal of Allergy and Clinical Immunology, vol. 120, no. 1, pp. 25-31, 2007.

[13] X. M. Li, T. F. Zhang, C. K. Huang et al., "Food Allergy Herbal Formula-1 (FAHF-1) blocks peanut-induced anaphylaxis in a murine model," Journal of Allergy and Clinical Immunology, vol. 108, no. 4, pp. 639-646, 2001.

[14] K. D. Srivastava, J. D. Kattan, Z. M. Zou et al., "The Chinese herbal medicine formula FAHF-2 completely blocks anaphylactic reactions in a murine model of peanut allergy," Journal of Allergy and Clinical Immunology, vol. 115, no. 1, pp. 171-178, 2005.
[15] S. P. Patil, J. Wang, Y. Song et al., "Clinical safety of Food Allergy Herbal Formula-2 (FAHF-2) and inhibitory effect on basophils from patients with food allergy: extended phase I study," Journal of Allergy and Clinical Immunology, vol. 128, pp. 1259-1265, 2012.

[16] J. Lee and K. T. Lim, "Inhibitory effect of phytoglycoprotein $(24 \mathrm{kDa})$ on allergy-related factors in compound 48/80-induced mast cells in vivo and in vitro," International Immunopharmacology, vol. 10, no. 5, pp. 591-599, 2010.

[17] H. R. P. Miller, S. H. Wright, P. A. Knight, and E. M. Thornton, "A novel function for transforming growth factor$\beta 1$ : upregulation of the expression and the IgE-independent extracellular release of a mucosal mast cell granule-specific $\beta$ chymase, mouse mast cell protease-1," Blood, vol. 93, no. 10, pp. 3473-3486, 1999.

[18] P. N. Pushparaj, J. Manikandan, H. K. Tay et al., "Sphingosine kinase1 is pivotal for FceRI-mediated mast cell signaling and functional responses in vitro and in vivo," Journal of Immunology, vol. 183, no. 1, pp. 221-227, 2009.

[19] P. S. Jolly, M. Bektas, A. Olivera et al., "Transactivation of sphingosine-1-phosphate receptors by FceRI triggering is required for normal mast cell degranulation and chemotaxis," Journal of Experimental Medicine, vol. 199, no. 7, pp. 959-970, 2004.

[20] C. A. Oskeritzian, S. E. Alvarez, N. C. Hait, M. M. Price, S. Milstien, and S. Spiegel, "Distinct roles of sphingosine kinases 1 and 2 in human mast-cell functions," Blood, vol. 111, no. 8 , pp. 4193-4200, 2008.

[21] L. C. H. Yu and M. H. Perdue, "Role of mast cells in intestinal mucosal function: studies in models of hypersensitivity and stress," Immunological Reviews, vol. 179, pp. 61-73, 2001.

[22] A. Olivera, N. Urtz, K. Mizugishi et al., "IgE-dependent activation of sphingosine kinases 1 and 2 and secretion of sphingosine 1-phosphate requires Fyn kinase and contributes to mast cell responses," Journal of Biological Chemistry, vol. 281, no. 5, pp. 2515-2525, 2006.

[23] M. M. Price, C. A. Oskeritzian, S. Milstien, and S. Spiegel, "Sphingosine-1-prosphate synthesis and functions in mast cells," Future Lipidology, vol. 3, no. 6, pp. 665-674, 2008.

[24] C. I. Ezeamuzie and E. S. K. Assem, "Anti-allergic properties of cyclosporin A: inhibition of mediator release from human basophils and rat basophilic leukemia cells (RBL-2H3)," Immunopharmacology, vol. 20, no. 1, pp. 31-43, 1990.

[25] S. Mitsutake and Y. Igarashi, "Calmodulin is involved in the $\mathrm{Ca}^{2+}$-dependent activation of ceramide kinase as a calcium sensor," Journal of Biological Chemistry, vol. 280, no. 49, pp. 40436-40441, 2005.

[26] W. Q. Lai, H. G. Hong, Z. Bao, W. S. F. Wong, A. J. Melendez, and B. P. Leung, "The role of sphingosine kinase in a murine model of allergic asthma," Journal of Immunology, vol. 180, no. 6, pp. 4323-4329, 2008. 


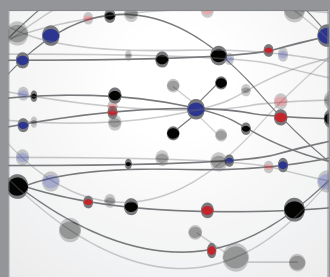

The Scientific World Journal
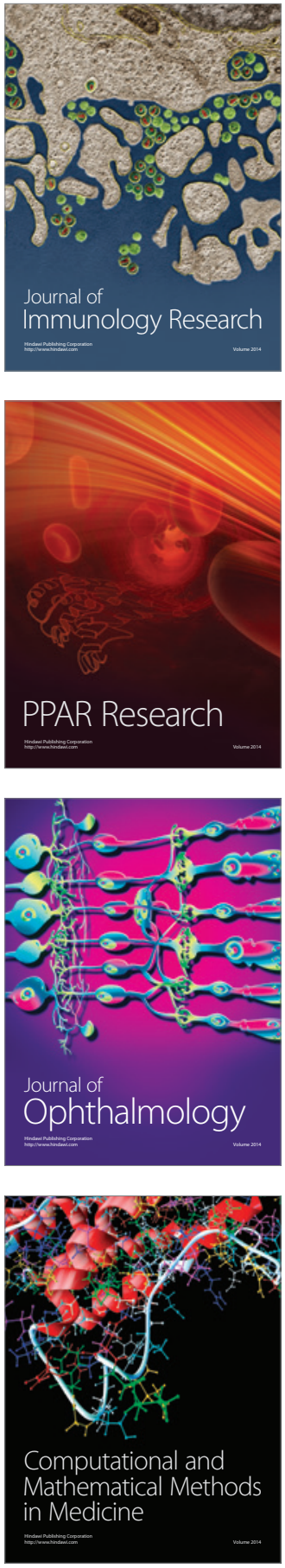

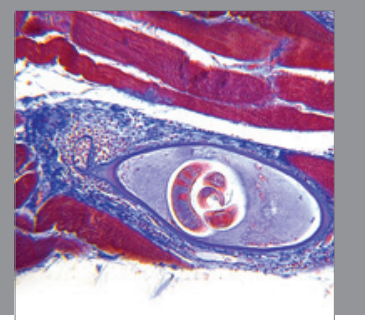

Gastroenterology

Research and Practice
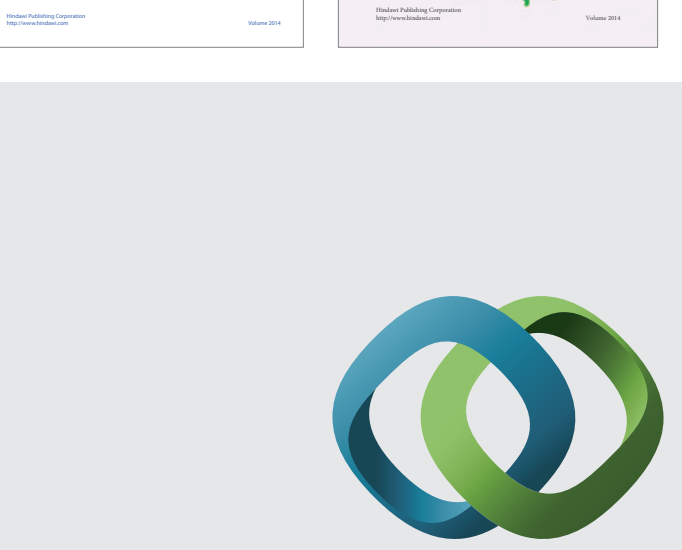

\section{Hindawi}

Submit your manuscripts at

http://www.hindawi.com
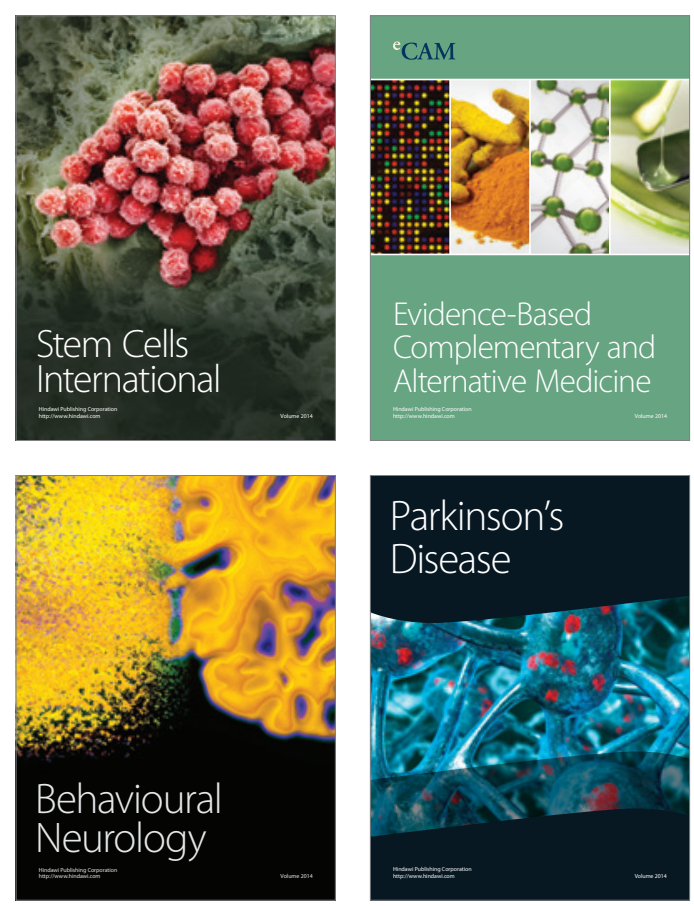

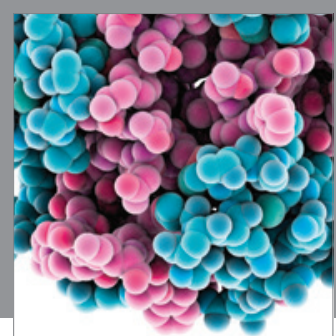

Journal of
Diabetes Research

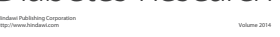

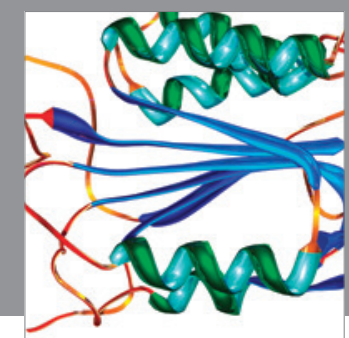

Disease Markers
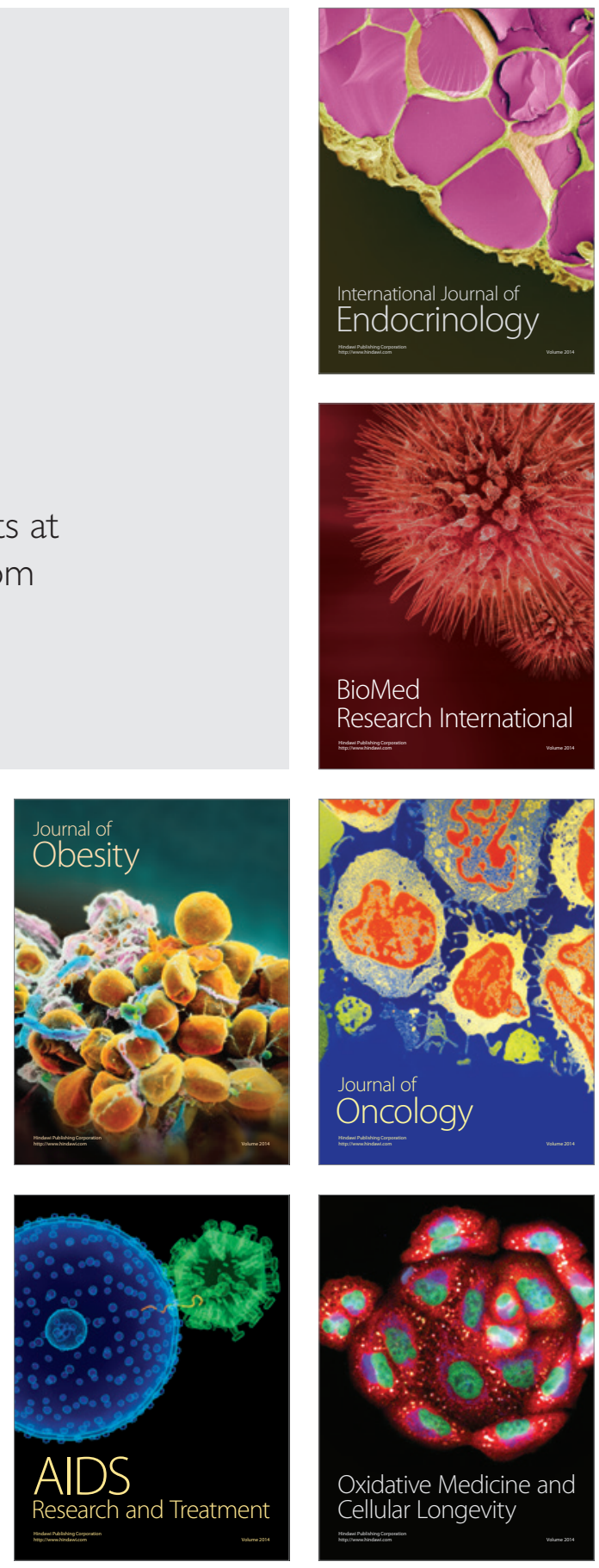